\title{
LENTIDÃO E NUANÇAS: A IDEIA DE MESTRE E CULTURA AUTÊNTICA EM NIETZSCHE
}

\author{
SLOWNESS AND NUANCES: THE IDEA OF A MASTER \\ AND AUTHENTIC CULTURE IN NIETZSCHE
}

\section{LENTITUD Y MATICES : LA IDEA DEL MAESTRO Y LA CULTURA AUTÉNTICA EN NIETZSCHE}

\author{
LÚCIA SCHNEIDER HARDT ${ }^{\mathrm{I}}$ \\ Paulo Becher Junior ${ }^{\text {II }}$ \\ 'Universidade Federal de Santa Catarina (UFSC), Santa Catarina/SC-Brasil \\ "Universidade Federal de Santa Catarina (UFSC), Santa Catarina/SC-Brasil
}

Resumo A educação, ao realizar um diálogo com a filosofia, amplia e problematiza o conceito de formação humana, inclusive as definições de maestria. Nesse cenário de reflexões, indagamos: seria a crítica, a estratégia por meio da qual o mestre faz uso da hesitação como um recurso pedagógico? Uma hesitação pautada pela lentidão e nuanças. Caberia a figura de um mestre com esse estilo dentro de um mundo que se caracteriza como veloz, onde o tempo não pode parar? Diante dessa proposta de formação, não é preciso pressa. Tornando-se amigo do tempo lento, há de ser possível perceber as sutis potencialidades escondidas na trajetória formativa de cada um, e, dessa forma, compreender que a filosofia da orientação proposta por Nietzsche se configura como um contínuo processo de reorientação e assim aprendemos a estreita relação entre a cultura autêntica e a noção do cultivo de si, condições necessárias para afirmar a vida, inclusive a considerar sua inteireza trágica. Para essa empreitada, mestres são necessários. A ação do mestre visa libertar o discípulo dos grilhões que aprisionam a sua formação aos interesses da sociedade, buscando desenvolver atividades que possibilitem a força humana de criação.

Palavras-chave: Formação; Nietzsche; Cultivo de si; Mestre.

ABstract Education, when carrying out a dialogue with philosophy, expands and problematizes the concept of human formation, including definitions of mastery. In this scenario of reflections, we ask: would it be criticism, the strategy through which the teacher makes use of hesitation as a pedagogical resource? A hesitation based on slowness and nuances. Would it fit the figure of a master with this style within a world that is characterized as fast, where time cannot stop? Given this training proposal, there is no need to rush. Becoming 
a friend of slow time, it must be possible to perceive the subtle potential hidden in the formative trajectory of each one, and thus understand that the philosophy of orientation proposed by Nietzsche is configured as a continuous process of reorientation and thus we learn to a close relationship between authentic culture and the notion of self-cultivation, necessary conditions for affirming life, including considering its tragic completeness. For this endeavor, masters are needed. The master's action aims to free the disciple from the fetters that imprison his training to the interests of society, seeking to develop activities that enable the human force of creation.

Keywords: Formation; Nietzsche; Self-Cultivation; Master.

RESUMEN La educación, al dialogar con la filosofía, amplía y problematiza el concepto de formación humana, incluyendo las definiciones de dominio. En este escenario de reflexiones nos preguntamos: ¿sería la crítica, la estrategia a través de la cual el docente hace uso de la vacilación como recurso pedagógico? Una vacilación basada en lentitud y matices. ¿Encajaría la figura de un maestro con este estilo dentro de un mundo que se caracteriza por ser rápido, donde el tiempo no se detiene? Ante esta propuesta de formación, no hay necesidad de apresurarse. Convertirse en amigo del tiempo lento, debe ser posible percibir las sutiles potencialidades que se esconden en la trayectoria formativa de cada uno, y así entender que la filosofía de orientación propuesta por Nietzsche se configura como un proceso continuo de reorientación y así aprendemos a una estrecha relación entre la cultura auténtica y la noción de autocultivo, condiciones necesarias para afirmar la vida, incluso considerando su trágica plenitud. Para este esfuerzo, se necesitan maestros. La acción del maestro tiene como objetivo liberar al discípulo de las cadenas que aprisionan su formación a los intereses de la sociedad, buscando desarrollar actividades que habiliten la fuerza humana de creación.

Palabras Clave: Formación; Nietzsche; Autocultivo ; Maestro.

\section{INTRODUÇÃo}

Nietzsche, em sua terceira Consideração Extemporânea (1874) - Schopenhauer como educador -, critica severamente o sistema educacional da Alemanha do século XIX. Nessa crítica, já é possível verificar a resistência do filósofo à pressa muitas vezes solicitada por uma propensão dos indivíduos ao comodismo, à preguiça. $\mathrm{O}$ oposto disso parece a lentidão, não para fixar-se e se proteger, mas exatamente para dar atenção às nuanças de tudo aquilo que desejamos aprender. Esse não é um caminho fácil, mas “aquele que não quer pertencer à massa só precisa deixar de ser indulgente para consigo mesmo; que siga sua consciência que lhe grita: Sê tu mesmo" (NIETZSCHE, 2003, p. 139). Ocupar-se das coisas do conhecimento implica tempo, lentidão, aversão à pressa, não ficar atrelado à pura formação "profissional", visando disputar uma vaga no mercado de trabalho, convertendo-se por vezes em rebanho. Mesmo que Nietzsche em sua trajetória filosófica vá alterando seus temas e prioridades, as questões da educação e da cultura sempre estiveram presentes. Concretizam-se vários estilos, mas sempre é destacado aquele indivíduo capaz de convo- 
car seu direito de dar atenção a si mesmo (cultivo de si ou "sê tu mesmo") nas múltiplas trajetórias que a vida oferece. Se o futuro é assustador, a singularidade de nossa existência pode nos encorajar a definir e criar outras e novas formas de viver, inclusive outros processos formativos. Por isso, afirma: "ninguém pode construir no teu lugar a ponte que te seria preciso tu mesmo transpor no fluxo da vida - ninguém, exceto tu" (2003, p. 140). E nesse caminho, conclui: "teus educadores não podem ser outra coisa senão teus libertadores" (p. 142). Formação, ${ }^{1}$ nessa direção, quer dar tempo às coisas que efetivamente são importantes, uma educação que é:

Somente libertação, extirpação de todas as ervas daninhas, dos dejetos, dos vermes que querem atacar as tenras sementes das plantas, ela é efusão de luz e calor, o murmúrio amistoso da chuva noturna; ela é imitação e adoração da natureza no que esta tem de maternal e misericordioso (NIETZSCHE, 2003, p. 142).

Assim, formar-se implica crescer, e exige também eliminação, resistência, extinção de algo. Nietzsche, ao afirmar essa outra educação, diz que o processo só acontece se de fato tivermos o privilégio de ter conhecido educadores e mestres; e nesse contexto faz sua homenagem a Schopenhauer. Esse mestre foi seu libertador, deu sinais e caminhos para extirpar ervas daninhas e vermes do seu itinerário. Mostrou o limite das instituições de ensino, e fez ver que uma formação, quando orientada para o "quanto mais, melhor", é muito nociva por se pautar apenas pelas necessidades econômicas e/ou de subsistência, deixando de lado a formação integral do homem.

Para Nietzsche, seu grande mestre foi Schopenhauer, um educador acima das fragilidades e insuficiências de sua época, um filósofo capaz de elevar alguém acima de sua própria realidade, capaz de "ensinar novamente a ser simples e honesto no pensamento e na vida, e portanto intempestivo, ${ }^{2}$ no sentido mais profundo da palavra" (2003, p. 146). Os excessos de formalismo e eruditismo criaram homens desonestos. De fato, Schopenhauer marcou a trajetória de Nietzsche, e mesmo que mais tarde tenha rompido com ele, isso ocorreu exatamente porque encontrou um mestre, que lhe ofereceu asas para voar sozinho. Portanto, a condição de mestre fica preservada. Aprendeu com ele a dizer o que é profundo de uma forma simples, "o que é estritamente científico sem pedantismo" (p. 148). Aprendeu com ele a salvaguardar sua própria existência, defendendo a todo custo sua filosofia contra a indiferença dos seus contemporâneos, ensinando "que a filosofia oferece ao homem um asilo onde nenhum tirano pode penetrar, a caverna da interioridade, o labirinto do coração: e isto deixa enfurecido os tiranos" (p. 154). Certamente, o isolamento também tem seu preço, ainda mais quando esteve presente "o desespero da verdade" (2003, p. 155) em contraposição a outras, dadas como as mais robustas e necessárias. E Nietzsche afirma:

1 Segundo Weber (2011), Nietzsche inicialmente utiliza a expressão formação (Bildung) vinculando tal expressão com a estética e a teoria da cultura. À medida que se distancia de Schopenhauer e Wagner cresce a referência ao termo Erziehung (educação), quase desaparecendo o primeiro termo. No texto, utilizaremos os dois conceitos já que a tradição no campo da educação nos autoriza a isso.

2 O caráter intempestivo em Nietzsche contempla uma crítica à modernidade, ao cientificismo, à ideologia do progresso e apesar disso não implica uma fuga do presente ou recusa do tempo histórico, sugere mesmo uma abertura ainda mais radical do próprio entendimento da historicidade da existência humana. 
Schopenhauer pode ser para nós depois de Kant- um guia que conduz das cavernas da melancolia cética ou da renúncia crítica para as alturas da contemplação trágica, com o céu noturno e suas estrelas no infinito acima de nós; ele foi o homem que primeiro deu a si próprio este caminho e o percorreu. Eis aí sua grandeza: ter-se colocado diante da imagem da vida como diante de uma totalidade, para interpretá-la como totalidade, ainda que os espíritos mais perspicazes não cheguem a desembaraçar-se do erro de que são acometidos nesta interpretação, quando examinam detalhamente as cores do quadro e a matéria sobre a qual é pintado; tendo como resultado talvez que se trata aí de um véu com uma textura particularmente sutil e que as cores aí colocadas não podem ser analisadas quimicamente. É preciso imaginar o pintor, caso se queira compreender o quadro (2003, p. 156).

A educação inspirada pela filosofia pode também percorrer esse caminho, contemplando o quadro e o pintor para refletir acerca das nuanças. Equivocamo-nos quando colocamos todo nosso olhar sobre uma parte; "pode-se mesmo dizer que unicamente aquele que firmemente envolveu com o olhar o quadro geral da vida e da existência se servirá das ciências particulares sem se prejudicar" (NIETZSCHE, 2003, p. 157), pois caso não considere a imagem reguladora do todo, acaba capturado por armadilhas tramadas por fios desfiados que não nos levam a lugar algum. Por essa direção, nos assevera Hermann, (2016, p. 1), "que a pesquisa educacional pode abrir-se aos questionamentos filosóficos, no sentido de trazer à cena aquilo que não está explicitado". Assim, o papel reflexivo e crítico da filosofia mantém a sua função questionadora, possibilitando à educação os meios para se afastar de um idealismo, ou ainda, de um encastelamento sobre si mesma, de um pedantismo pedagógico. Ao valer-se da atuação perturbadora da filosofia e promover a experiência do pensar, a educação pode evitar a possibilidade de uma fragilidade teórica ou, ainda, a predominância irrefletida de um empirismo absoluto. Isso dialoga com as tintas, as cores, os véus, o quadro e talvez com as sementes, luz e vermes. Nietzsche emparelha educação e natureza, ao invés de excluir uma delas. Por isso, os métodos de educação como antinaturais impedem a formação, não permitem fazer perguntas para trazer à cena o que ainda não está explicitado. Cabe à educação, então, libertar a força que a natureza destinou aos homens para a sua elevação e realização: são forças constituídas por muitas tintas, pincéis que permitem a todo indivíduo realizar sua obra, pintar seu quadro, dando provas que é capaz de pensar por si mesmo, debruçar-se sobre a própria experiência e criar medidas e valores. A educação deve ser o caminho para "tornar-se o que se é".

Nesse sentido, a aplicação metodológica da filosofia de Nietzsche pode ser um desses motes de interação entre a filosofia e a educação. A pergunta é: Como operar pedagogicamente com Nietzsche? Parece possível promover a interlocução entre o "filósofo do martelo", processos formativos e a presença de um mestre efetivamente. Nietzsche considera que o destino do filósofo seja pensar. No entanto, o "pensar" nietzschiano não tem pretensões à universalização, e tampouco tem olhos apenas para os "véus e cores, sem reparar o próprio quadro" (2003, p. 157).

Em alguma medida, ainda nessa primeira etapa de sua filosofia, é defendida uma cultura autêntica que não será efetivada pela formação de indivíduos em série, em um processo absolutamente impessoal. Nietzsche defende uma educação individualizada (que conduza 
ao cultivo de si!), passada de mestre a discípulo, por meio de uma relação respeitosa e de admiração. Por isso, nesse texto, a exacerbação da necessidade de um mestre - visualizado então por Nietzsche, em seu caso pessoal, na figura de Schopenhauer. Existe uma valorização do que é singular, será preciso conhecer as próprias misérias, limites, entender quais remédios e consolações são oferecidos, para dar a si mesmo um objetivo elevado do humano: trata-se de transfigurar, conquistar algum poder para enfrentar aquilo que é possível e encontrar um lugar para habitar e viver. Todos os modelos universais e todas as coisas dadas como particulares podem ser novamente contempladas e perceber como conectamos nossa vida com tudo isso e nesse processo aparecem também nossos limites e incompletudes.

O ímpeto de Schopenhauer era dar à cultura sua verdadeira dimensão, o que poderia também advir da gestação e criação de um gênio que decifrasse novos caminhos. Mas o pulsar do gênio é sempre frágil, raro, está nele uma natureza impetuosa da curiosidade, mas também certa melancolia, pois percebe que aquilo que foi visto por um homem não migrará para outros. Este foi um dos seus grandes dilemas, não compreendido em sua época. O que aprendemos nesse particular é que o filósofo ainda pode ser um modelo para nós, e, por meio de sua maestria, ele nos desafia a não desistir de buscar em nós mesmos algo de genuíno, vencendo o que em nós é preguiça e covardia. Não somos gênios, mas algo originário pulsa em cada um de nós. Viver é estar em perigo, desertos e cavernas estão sempre entre nós, e para isso devemos refletir sobre valores: "para ser justo para com a existência em geral, quanto não lhe seria preciso acrescentar ao sem-valor da época atual" (NIETZSCHE, 2003, p. 161). Superar a mediocridade: esta é a tarefa de um filósofo; e não seria também do educador? O que hoje acrescentaríamos aos conteúdos propostos aos nossos alunos, que nem de perto vêm sendo reconhecidos como necessários? Como estamos avaliando a pedagogia de nossa época? Existe um lugar para o "cultivo de si" nos termos propostos por Nietzsche?

Segundo Costa Dias (2017), o grande mérito de Schopenhauer como educador, para Nietzsche, foi ter sido um modelo que inspira uma postura de crítica diante de sua época. Ele é intempestivo, não é um homem sob medida para seu tempo, decifra e revela atrocidades desse tempo e quer se livrar dos vermes e das ervas daninhas. Isso é o que o torna grande, isso inspirou Nietzsche por toda a vida. De Schopenhauer, ele ganhou asas para voar sozinho.

Nietzsche, ao propor sua reflexão filosófica, destoa do pensamento moderno e se concentra em duas categorias a saber: o lento e a nuança.

Esses dois elementos deixam transparecer uma possível discussão pedagógica operada pela filosofia de Nietzsche: do mestre que solicita ao discípulo para tartamudear frente ao que se aprende, para ali perceber as sutilezas do processo formativo, ${ }^{3}$ não como algo fixo em uma determinação de tempo. Costa Dias (2017) destaca que é preciso identificar o que Nietzsche enfrenta em sua época para, na esteira dessa reflexão, pensar nosso tempo:

\footnotetext{
O fato é que a aquisição do conhecimento organizado e transmitido no interior da escola, e este, por sua vez, compreendido como espaço formativo tradicional, tem por meta e escopo de sua atuação a garantia da conquista e sedimentação de saberes que se tornam cristalizados, pois são conquistados de modo definitivo. No entanto, com os desafios prementes que hoje se apresentam para o processo formativo, o processo de aprendizagem se ocupa com questões que transcendem a aquisição das diversas formas de saberes construídos e preservados pela cultura ao longo do tempo. Além destes, se faz mister apontar a necessidade da formação de si. E a última tarefa, tão necessária quanto a primeira, se caracteriza como um exercício itinerante, onde as nuances não são meros detalhes, mas, sim, parte constitutiva das essencialidades da formação.
} 
...uma cultura que converteu-se em um agrupamento de caprichos momentâneos, moda, opinião pública e cultura jornalística na qual os homens "estudam" para "aprender a ganhar dinheiro" e ganham dinheiro para consumir, mantendo o sistema em movimento - e, muitas vezes, consumir "bens culturais", pois até a cultura parece se tornar um grande comércio (p. 285).

Aqui, parece oportuna a indagação: Existem hoje mestres para refletir sobre questões dessa natureza, ou estamos apressados em nos ajustar aos tempos modernos para nos abrigar em espaços institucionais confortáveis?

Teria espaço na realidade pedagógica atual um mestre que apela para a hesitação como um recurso pedagógico? Cabe ainda no cenário formativo a figura de um mestre que desperta para a observação dos detalhes (nuanças), dentro de um mundo que se caracteriza como veloz, onde o tempo sempre deve ser "aproveitado"? Onde sempre somos convidados a nos atualizar para ficarmos parecidos com nosso tempo?

Por isso, convém observar as recomendações de Nietzsche:

\begin{abstract}
...duas coisas se opõem à cultura autêntica: o "egoísmo dos negociantes" e o "egoísmo do Estado", que são os grandes responsáveis pela transformação da cultura em mera cultura utilitarista, um misto de bem de consumo e formação para o trabalho, que é a formação moderna do jovem, apresentando apenas dois objetivos, ligados entre si: educar para ganhar dinheiro, porque é o dinheiro - e nada mais - que trará felicidade, e formar para trabalhar, para adequar o jovem aos meios de produção, integrando-o às instituições já existentes e conformando-o à sociedade vigente (COSTA DIAS, 2017, p. 286).
\end{abstract}

\title{
O MESTRE E O SEU LENTO AGIR
}

Ser lento e observar nuanças é perceber como a educação a serviço do Estado pode ser um instrumento de regulação para ajustar indivíduos ao mercado. Não se trata de desvalorizar a escola e sua dimensão pública, mas antes evitar seu processo de mediocrização. É não permitir que o espírito pedagógico se ajuste ao mínimo, deixando de considerar a formação individual de cada estudante. Não consentir, conforme Nietzsche afirma, que se instale uma espécie de barbárie cultivada.

O filósofo/mestre revelado em Nietzsche constrói o seu pensamento a partir do "desejo de se ver mais ao longe, de encontrar 'verdades mudas', silenciadas" (MANIERI, 2007, p. 61). Quando propõe o desenvolvimento da vida humana e dentro dele depara-se com a ideia de perspectiva, a reflexão nietzschiana deixa transparecer a condição da transformação como algo permanente. A formação, e por consequência a vida humana, está em um devir constante. Segundo Pena (2012, p. 130), Nietzsche considera que "a formação, a modernidade e os seus impasses, consiste em aprender, sem concessões ou facilitações, que o homem é tempo e, por consequência, inacabamento".

O próprio tempo, pode-se dizer, é que configura o envolvimento entre o mestre e os seus discípulos. Afinal de contas, vivências dessa natureza nem sempre são consolidadas em um curto espaço de tempo. O envolvimento desses agentes com o intuito de "criar uma 
presença (comum)" (MASSCHELEIN; SIMONS, 2014, p. 165) no ato pedagógico pressupõe uma convivência. Portanto: mestre e discípulo sucumbem, juntos, no tempo em que ambos vivenciam essa relação. No estudo de caso, exposto neste texto mesmo que parcialmente, considerando Nietzsche e Schopenhauer, assistimos o mestre em questão educando o discípulo contra seu tempo, pois conhece o tempo onde vive e, para além das cores, tintas e véus, consegue a seu modo decifrar o tempo e indagar: "no mais profundo do teu coração, dizes sim a esta existência?” (NIETZSCHE, 2003, p. 163).

No seu texto intitulado Aurora, especificamente no prólogo da obra, Friedrich Nietzsche acena para algumas atitudes desejáveis dos seus leitores, que ele mesmo considera fundamentais, para que possam ser entendidos os seus escritos. Ao exclamar "aprendam a me ler bem" (NIETZSCHE, 2008, p. 23), o autor sintetiza a sua relação com os seus leitores a partir de uma específica consideração ao tempo. Essa relação se apresenta na contramão da pressa, como que em um postulado pela atitude de hesitar diante de determinada realidade. Nietzsche, enquanto mestre, vamos assim aqui o considerar, propõe um aprendizado lento. Que não tem a obrigação de reagir imediatamente.

Nos dias atuais, no interior da escola, é possível encontrar espaço para essa pretensiosa operação? Caberia em nosso tempo falar de uma "pedagogia da hesitação"? Tais questionamentos parecem pertinentes dentro de uma realidade escolar, tantas vezes, delineada por atitudes conteudistas. ${ }^{4}$ Tal delineamento sugere uma oposição ao pensamento de Nietzsche. Isso porque uma realidade tida como conteudista parece não considerar o tempo de maneira lenta, como um procedimento pedagógico eficaz. Ao contrário, a verificação dos muitos conteúdos desenvolvidos pelo professor exige um tempo cronometrado, recheado de atividades que possam mensurar a assimilação de tudo que foi supostamente ensinado e aprendido. E muitas vezes, apesar da carga de conteúdo, de fato não estamos acrescentando nada de original para fazer pensar nosso aluno. Uma organização pedagógica com esses caracteres acaba por privilegiar a mensuração do quanto se foi absorvido das informações ali transmitidas. Nietzsche, por sua vez, se apresenta como um "professor de leitura lenta" (NIETZSCHE, 2008, p. 23) e o seu modo de ensinar ao escrever percorre a mesma senda.

Nietzsche, ainda no tão conhecido prólogo de Aurora, apresenta indicativos para se operar de modo lento com o tempo, entre os quais se destaca a sutileza. Como "amigo do lento", é nessa calma e desapressada consideração que sutilmente é possível descobrir as diversas perspectivas (interpretações). ${ }^{5} \mathrm{O}$ trabalho apressado não percebe os sutis detalhes. Aquilo que é realizado de modo apressado pode ficar marcado pela mediocridade da média; por aquilo que é comum. Pode não se tornar profundo, ou ainda, consistente. No entanto, o autor faz questão de alertar que tal ofício pode assustar o apressado mundo atual, de trabalho precipitado e raso (NIETZSCHE, 2008, p. 23). Dessa maneira, o trabalho do mestre

4 Diz-se como conteudista a escola que se organiza de modo centrado na figura do professor, enquanto elemento de transmissão de informações culturais. Também se encontra um modelo de avaliação onde se considera importante a quantidade de informações apreendidas.

5 Segundo Sousa (2016), interpretação é um meio de se apoderar de algo, implica movimento, devir, transformação, mudança de sentido. Já o perspectivismo nietzschiano aponta para uma ampliação da visão de mundo, leva o humano a uma abertura do seu leque de interpretações sobre o seu viver e sobre as suas relações com os outros e com o mundo. O perspectivismo não encarcera a visão, o sentir. Ele torna crítica uma pessoa, não permitindo que ela permaneça fechada em sua própria perspectiva. 
demonstra ser "a arte da vida lenta" (STEGMAIER, 2013, p. 287) e se realiza por meio de nuanças.

A nuança é reveladora dos pequenos detalhes, daquilo que ficou despercebido, ou ainda aquilo que realizado de modo rápido não pode ser sabido. Considerando esses pontos de sustentação da sua prática, o lento e a nuança, os discípulos do mestre Nietzsche são aqueles que conseguem "dar tempo ao tempo". Ou seja, aqueles que não buscam no mestre uma solução já pronta e acabada. Rápida, por assim dizer. A possibilidade do inacabado demonstra novas descobertas, um deslocamento em relação a uma verdade única. "Constrói um novo caminho para 'verdades silenciadas' e 'realidades vencidas"” (MANIERI, 2007, p. 61). Assim, o mestre, aos moldes nietzschianos, não foge, não nega e não se esconde do inesperado, que sempre pode surpreender. $\mathrm{O}$ mestre que se desenvolve com a filosofia de Nietzsche não teme pela surpresa, por aquilo que não estava programado. Stegmaier (2013, p. 288) sinaliza para essa consideração quando assegura que Nietzsche, ao escrever:

(....) não pretende 'terminar logo com alguma coisa tão facilmente', inclusive não quer o acabado, o definitivo, o conclusivo, mas sim persegue 'segundas intenções', deixa as portas abertas, atrás das quais se pode ainda indicar algo a mais, algo inesperado.

A categoria nuança, enquanto capacidade de perceber sutis diferenças, contrapõe-se à definição (colocar entre fins). Isso, por sua vez, demonstra o fixo. Em certa medida, a abertura da nuança ao inesperado se mostra como uma resposta ao já acabado. E por assim dizer, não seria essa também uma provocação para a educação? Como se apresentar, ou ainda mais, como operacionalizar uma proposta pedagógica aberta ao deslocamento, superando a rigidez daquilo que se fixa como modelo e parâmetro? O conceito de nuança pode propor uma "superação do tempo", a partir de uma "superação de si". Na possibilidade de construir a individualidade livre, como uma forma de não reagir imediatamente aos estímulos sofridos. De ter coragem para hesitar. Ou, nas palavras de Nietzsche, "aquela arte da filigrana do prender e aprender, aqueles dedos para nuanças, aquela psicologia de "ver além do ângulo"” (NIETZSCHE, 2008, p. 22).

O mestre/filósofo parece acenar para um caminho de compreensão da realidade e, por conseguinte, de orientação, que escapa da apresentação de um modelo único e padronizado, identificado com uma verdade tida como absoluta. Na perspectiva nietzschiana, a autenticidade humana subjaz o caráter do indivíduo, denunciando a existência de uma espécie de preguiça ao se conformar com as padronizações. "Para compreender a orientação cotidiana, a filosofia tem que deslocar-se da certeza a incerteza" (STEGMAIER, 2013, p. 309). Desse modo, a orientação do mestre, no sentido nietzschiano, desvela a "necessidade de se obter um 'estilo próprio', (cultivo de si) sem o qual cada homem não passaria de produto de fábrica ou artigo fabricado, inautêntico quanto ao pensar e quanto ao caráter" (DEBONA, 2013, p. 179).

A trajetória da formação em Nietzsche, na qual é possível deparar-se com uma filosofia da orientação, deixa transparecer o caminho da modificação. Da criação de si mesmo, da liberdade de um indivíduo que se torna aquilo que deveria ser. "Criar é a grande eman- 
cipação da dor e o alívio da vida" (NIETZSCHE, 2008, p. 119). O "espírito livre"6 realiza o processo formativo indo além das definições previamente delineadas, apresentando-se como experiência.

O processo de uma filosofia da orientação, inspirado pelo Mestre em Nietzsche, pode se realizar dentro dessa dinâmica de “experimentação". É aí que a formação pode apresentar-se como múltipla, superando, assim, matizes que passam a entendê-la como um fenômeno cristalizado, monolítico, que sugere um modelo de características petrificadas. De outra maneira, poderia se pensar a formação como um processo envolto pela prática de um "espírito livre" que possa superar a aceitação passiva e obediente daquilo que lhe ensinam. "Assim pois, para falar sem rodeios: é necessário que nos sintamos irritados verdadeiramente, para que tudo fique melhor" (NIETZSCHE, 2003, p. 171). Isso implica coragem, afirmação da vida e enfrentamento da dor.

Nesse direcionamento, a possibilidade orientadora da filosofia do mestre Nietzsche sinaliza para uma compreensão da "realidade da formação", com caracteres provenientes do dinamismo, da mutabilidade, da contínua modificação dela mesma. Essa compreensão estaria "livre da pretensão da estabilidade e fixidez inerente à racionalidade, a 'realidade' passa a apresentar-se como marca característica do devir, do tornar-se" (RICCI, 2007, p. 40). Diante dessa proposta de formação, não é preciso pressa. Tornando-se amigo do tempo lento, há de ser possível perceber as sutis nuanças escondidas na trajetória formativa de cada um, e, dessa forma, compreender que a filosofia da orientação proposta pelo mestre de Nietzsche se configura como um contínuo processo de reorientação, sempre que necessário. A caminhada com o tempo sugere essa ideia de um deslocamento insuperável.

Com o vigor apresentado por Nietzsche em sua filosofia, postular uma trajetória da orientação é percorrer um caminho que se distancia de um marco final no processo orientador. O mestre que se exibe a partir de Nietzsche é um incentivador de vontades particulares. É preciso recordar que o mestre prefigurado no professor Nietzsche não se furta do inesperado. Desse modo, parece que a possibilidade da orientação, na perspectiva do referido autor, se configura com caracteres de liberdade e redirecionamento. Ricci $(2007$, p. 42) reflete da seguinte maneira:

A ênfase nietzschiana na questão do tornar-se, ao invés de postular uma evo-
lução, como fizeram muitos pensadores - entre eles o próprio Darwin que
Nietzsche atacaria duramente, especialmente nos seus escritos dos ditos segun-
dos e terceiros períodos. Uma 'realidade' em constante transformação, num
dinamismo ininterrupto, onde forças ora sobrepujam ora são sobrepujadas, não
deixa lugar para alguma finalidade teleológica. Não haveria como supor esse
cenário que uma força é 'melhor' que outra e, em determinado momento, elas
atingiriam um equilíbrio tal que a luta de forças terminasse finalmente com a
vitória das forças 'melhores'. Por não poder se supor uma finalidade, um dire-

6 É chamado de espírito livre aquele que pensa de modo diverso do que se esperaria com base em sua procedência, seu meio, sua posição e função, ou com base nas opiniões que predominam em seu tempo. Ele é a exceção, os espíritos cativos são a regra [...] De resto, não é próprio da essência do espírito livre ter opiniões mais corretas, mas sim ter se liberado da tradição, com felicidade ou com um fracasso. Normalmente, porém, ele terá ao seu lado a verdade, ou pelo menos o espírito de busca da verdade: ele exige razões; os outros, fé (NIETZSCHE, 2000, p. 157). 
cionamento 'fatal' da 'realidade', também não se poderia imaginar uma meta. Esse raciocínio que abarcaria o mundo, obviamente também seria válido para os indivíduos, posto que esses estão aí inclusos. Não poderíamos traçar aí um objetivo, um alvo certo para as nossas vidas porque estaríamos constantemente nos tornando aquilo que somos, estaríamos em constante transformação.

Tanto o pensamento quanto a ação, do mestre e do discípulo, caminham por um processo de constante reorientação. "O filósofo deve interrogar a si mesmo, seu tempo e sua vida, para ser "reformador da vida"” (NICODEMO, 2014, p. 222).

Nesse direcionamento reformador, "o tempo significa, para a orientação, que tudo sempre pode tornar-se de outro modo" (STEGMAIER, 2013, p. 308). Inclusive a própria finalidade da ação formativa. No aforismo 21 da Gaia Ciência (1882), se encontra a seguinte consideração:

A educação procede quase sempre assim: ela procura encaminhar o indivíduo, por uma série de estímulos e vantagens, para uma maneira de pensar e agir que, quando se torna hábito, impulso e paixão, vigora nele e acima dele, de encontro com a sua derradeira vantagem, mas "para o bem de todos" (NIETZSCHE, 2001, p. 71).

A educação tradicionalmente considerada forma para atender às demandas do grupo social. E assim parece se constituir, em detrimento dos anseios particulares. Desse modo, o processo formativo cumpre uma programação elaborada pela sociedade, representada no poder organizado do Estado, sendo este o ente que dita as normas, funções e processos para a educação. A formação passa a ser generalizada, disposta de forma comum a todos e, por ser assim, se apresenta tantas vezes de modo estéril. Como o mestre em Nietzsche pode sugerir o contrário dessa realidade? Por intermédio da crítica. ${ }^{7}$ À medida que o mestre continua a fazer pensar, estimula a configuração de outros modos de ser da subjetividade. Ou seja, é capaz de deslocamento e reorientação.

Tantas vezes a escola parece levar o mestre para uma relação informativa para com os seus discípulos, tendo em vista o alcance de bons índices de desempenho nos exames pretensamente qualificadores do processo educacional. Eis aí uma demonstração da "vantagem para todos". Por não ser dotada de sentido para o discípulo, este acaba vivendo a educação com alguns dos adjetivos apresentados no referido aforismo: de maneira modesta, irrefletida, indiferente e irônica. Deslocar a compreensão das razões da educação, evidenciando o que nela é ignorado, por meio das sutis nuanças que ficam despercebidas, pode ajudar a reconfigurar o significado da ação pedagógica. Afinal, se estuda para quê?

A dimensão do mestre em Nietzsche tem muitas nuanças e estamos nos autorizando neste texto a fazer dançar entre as linhas essas múltiplas perspectivas, e isso com o vigor do pedagógico, que escapa dos procedimentos usuais para fazer acontecer outra reflexão. Assim, voltemos outra vez ao modelo schopenhauriano, muito destacado por Nietzsche e

7 Nietzsche usa o termo "ruminar" para referir-se a uma crítica que exige ao mesmo tempo lentidão, o que em nosso texto fica também expresso pela palavra hesitação contemplando assim um olhar crítico sobre o presente, enfrentando a precipitação por meio da lentidão e a pressa desenfreada do homem moderno pelo exercício da paciência. 
nunca totalmente abandonado em sua condição de mestre. Ele recorda sempre que é preciso "ser puro consigo mesmo, ter serenidade em relação ao conhecimento, ser cheio de fogo forte e devorador e estar bem longe da neutralidade fria e desprezível do pretenso homem de ciência" (NIETZSCHE, 2003, p. 172).

A dimensão do mestre clama inclusive por outra noção de ciência, pois oferece a si mesmo como "objeto" para análise daquilo que naquele instante considera plausível, o que exigirá colocar em questão amigos, instituições formadoras e determinadas convicções de época. Como diz Schopenhauer, destruindo em parte uma possível felicidade terrestre. A coragem de colocar-se em questão para investigação pode ser outra afirmação da vida, muito diferente daquela na qual o homem se esquece de si mesmo para jogar o jogo estúpido de ser apenas cidadão, consumidor ou um homem de Estado. Esse conjunto de coisas deveria nos ajudar a extrair desse ideal outro ciclo de deveres. Portanto, existe um legado em Schopenhauer que educa; contudo, os efeitos desta formação alcançam outros patamares no corpo de Nietzsche.

Com esta análise, o filósofo/mestre parece não validar uma construção formativa que procure impor o conhecer e o agir como se fossem fundamentos uníssonos. De outro modo, busca elucidar que a constituição possível ao discípulo é a ação de fundar, valorar, impor, diferenciar-se inclusive do mestre. Ou seja, apresenta um sujeito dotado de um ato criativo, munido de uma espécie de forma de interpretação que impõe sua perspectiva inclusive no campo da moral. "A interpretação instituidora de novos valores, por parte dos futuros poderosos só pode ser, do mesmo modo, perspectivas" (NIETZSCHE, 1998, p. 47).

Nietzsche sugere que o processo de formação do discípulo é um trabalho que não se limita à sua importância para a sociedade. O discípulo deve buscar na sua relação com o mestre o seu desenvolvimento pessoal. A ação do mestre visa a libertar o discípulo dos grilhões que aprisionam a sua formação aos interesses da sociedade, buscando desenvolver atividades que possibilitem a força humana de criação. Cada discípulo, se efetivamente bem educado, deve saber lidar com as sombras, lançar luz sobre a sua própria existência, avançar onde for possível, recuar evitando alvos desnecessários, recolher-se na solidão quando possível, para elevar-se em direção a novos deveres e uma humanidade.

\section{CONSIDERAÇÕES FINAIS}

O legado moderno pode deixar transparecer uma proposta moral permeada pelos caracteres de uma condução formativa totalizante, com a busca de um princípio único para o fundamento do ato formativo, e até mesmo da moral. Dessa forma, por assim dizer, também estabelece uma prática teleológica igualmente única. De sorte que Zatti $(2005$, p. 1) considera:

\footnotetext{
A tradição do pensamento filosófico apresenta as construções éticas como reflexões sobre o agir em busca de um elemento último como seu definidor. Nesse sentido, procuram-se estabelecer máximas universais e validade incondicional. A ética kantiana, por exemplo, atribui à razão o governo absoluto quanto à moralidade, o que possibilita a universalidade de sua legislação. O projeto pedagógico moderno traz uma proposta de educação como uma ética aplicada, baseando-se na metafísica aspira a universalidade.
} 
Nietzsche parece não apresentar um caminho único para a formação. O que alguns de seus escritos podem sugerir é a trajetória dentro de um processo em que o indivíduo pode livrar-se daquilo que o prende em relação a sua experiência. Isto é, daquilo que o atrapalha em relação à compreensão das "pregas" que permeiam a vida social, e não tem valor. O espírito livre, dessa forma, oportuniza ao ser humano fazer as experiências que o levam a "tornar-se aquilo que se é". Nesse direcionamento, Nietzsche (2008, p. 295) salienta que:

Saber até onde vai o caráter perspectivista da existência ou mesmo saber se a
existência possui ainda outro caráter, se uma existência sem interpretação, sem
"sentido", não se torna um "absurdo", se, por outro lado, toda existência não é
essencialmente interpretativa - é o que, como correto, não pode ser decidido
pelas análises e pelos exames do intelecto mais assíduos e mais minuciosamente
científicos: uma vez que o espírito humano, durante essa análise, não pode agir
de outra forma do que ser ver sob suas próprias perspectivas e unicamente assim.

Criticando tais estereótipos, Nietzsche apresenta a condição humana, no que tange à fruição da vida e à formação, a partir dos conceitos de: interpretação, experiência, responsabilidade, escolha e seletividade. Tais conceitos deixam transparecer um projeto formativo autônomo, livre, que se reinventa em uma espécie de fluxo contínuo da vida, pautado pela nuança e pela lentidão.

Segundo Diaz (2014, p. 23), Nietzsche luta contra uma educação de massas e sobretudo contra um Estado que se apresenta como educador; está interessado no unicum, na singularidade, na diferença. A cultura transmitida pela educação deve dar condições, portanto, para promover a "autenticidade", aquilo que é "o genuíno" em cada estudante.

Assim, o ser humano é chamado a ser ele mesmo, no entanto, por medo e preguiça, o sujeito é construído a partir de disposições externas, e conforme Diaz (2014), o importante é compreender que a cultura autêntica, entendida como criação, precisa de esquecimento ou de certa quantidade de esquecimento, a fim de obter energia e se permitir dizer o novo, e não ser esmagada pelo que já foi dito ou pela força da tradição. Exige um espírito livre capaz de fermentar sua própria singularidade, uma busca incansável daquilo que em cada um de nós é original.

Parece possível, então, investigar a formação, inspirando-se na filosofia de Nietzsche, como um processo de transmutação, de modificação em relação àquilo que "se deve ser". Pensando a formação dentro do prisma da "vontade criadora" apresentada na filosofia de Nietzsche, que leva o indivíduo a conceber a sua existência de tal modo que "marcada indelevelmente, pelo estar em movimento do superar a si mesmo" (FEITOSA; BARRENECHEA, 2000, p. 158), esta pode ser encontrada dentro de um fluxo de criatividade que coloca o indivíduo nessa disposição de uma constante travessia. O dinamismo formativo oriundo dessa filosofia da educação parece conduzir o ser humano para a realização da "sua" obra por excelência. Isto é, a própria vida. Então, uma filosofia da orientação em Nietzsche poderia se constituir a partir de categorias como mudança e câmbio. Reveladoras de uma "vontade de poder" que está presente na própria vida.

No decurso desse pensamento, Feitosa e Barrenechea (2000, p. 157) asseveram: 
a experiência, jogando-o para frente, rumo a outra. O tempo que encerra uma experiência, mas que não cerra as portas ao porvir. As realizações, nessa tônica, ocorrem no tempo certo, como as estações: tempo de semear e de colher. Tempo de trabalhar e de celebrar. Tempo que, em seu movimento fluídico, desfaz as formas impedindo-as de se eternizarem. Tempo, em cujo transcurso, forma, desenforma e volta à forma des-forma, sucessivamente.

A filosofia da educação a partir dos pressupostos nietzschianos pode sugerir uma perspectiva de uma filosofia da orientação que se constitui pela ideia de movimento. Do contrário, é possível considerar que a permanência limita, cristaliza e dimensiona. O "vir a ser", o "tornar-se", são impulsos que transformam e constroem, dentro de uma dinâmica que indica um fluxo que se forma e desforma sucessivamente.

O mestre que se apresenta possível em Nietzsche, diante do já exposto, parece ter um prazo de validade. Não pela simples possibilidade de se tornar obsoleto, mas pelo fato de o discípulo daqui a pouco não precisar mais dele. A ideia de mestre em Nietzsche não parece formar para a constituição do espírito cativo. Deseja formar espíritos livres. Considera como indesejados tanto aqueles que "não sabem dizer não", quanto aquele que considera sempre o "meio a meio". Fato é que se deparar com o mestre Nietzsche, vasculhando calmamente o que as sutilezas do seu pensamento revelam, é ser sempre mexido; poder sempre ser deslocado; saber-se sempre capaz de reorientação.

Nessa trajetória, dar aos humanos condições de buscar em si mesmos algo de genuíno, uma espécie de obra de arte de si mesmo, é meta possível da relação mestre-discípulo por meio de uma educação autêntica. A educação como cultivo de si é aquela na qual o processo formativo é interminável, podendo ser aperfeiçoada por toda a vida, desde que saibamos dar atenção às nuanças com toda a lentidão que se faça necessário.

\section{REFERÊNCIAS}

COSTA DIAS, Luciana. A educação como formação ou "cultivo de si" em Friedrich Nietzsche. Filosofia e Educação [RFE] - v. 8, n. 3 - Campinas, SP, out. 2016/jan. 2017.

DEBONA, Vilmar. Para não figurarmos como produto de fábrica: Schopenhauer, Nietzsche e as noções de "caráter adquirido" e de "tornar-se o que se é". Estudos Nietzsche, Curitiba, v. 4, n. 2, p. 157-180, jul./dez. 2013.

DIAZ, Andrea Genis. El genio y lo genuino que hay em nosotros, vigencia del pensamiento educativo em Nietzsche. Filosofia e Educação - v. 6, n. 1, fev. 2014.

FEITOSA, Charles; BARRENECHEA, Miguel A. (Org.). Assim falou Nietzsche: memória, tragédia e cultura. Rio de Janeiro: Relume Dumará, 2000.

HERMANN, Nadja. Pesquisa educacional e filosofia da educação: busca de permeabilidade. XI ANPED SUL. Reunião Científica Regional da ANPED. UFPR; Curitiba, PR, 2016. 
MANIERI, Dagmar. O senso crítico em Nietzsche. Fragmentos de cultura, Goiânia, v. 17, n. 1/2, p. 61-75, jan./fev. 2007.

MASSCHELEIN, Jan; SIMONS, Maarten. Em defesa da escola: uma questão pública. Tradução Cristina Antunes, 2. ed. Belo Horizonte: Autêntica Editora, 2014.

NICODEMO, Nicola. Conhecimento e vida como progresso de transfiguração produtor de sentido: sobre razão poética, arte e perspectivismo em Nietzsche. Estudos Nietzsche, Curitiba, v. 5, n. 2, p. 215-256, jul./dez. 2014.

NIETZSCHE, Friedrich. Aurora. Reflexões sobre os preconceitos morais. Trad. Mario D. Ferreira Santos. Petrópolis, RJ: Vozes, 2008.

NIETZSCHE, Friedrich. A Gaia Ciência. Tradução de Paulo César de Souza, 2. ed. São Paulo: Companhia das Letras, 2001.

NIETZSCHE, Friedrich. Genealogia da moral: uma polêmica. Tradução de Paulo César de Souza. São Paulo: Companhia das Letras, 1998.

NIETZSCHE, Friedrich. Humano, demasiado Humano: um livro para espíritos livres. Trad. Paulo César de Souza. São Paulo: Companhia das Letras, 2000.

NIETZSCHE, Friedrich. III Consideração Intempestiva: Schopenhauer educador (1874). In: NIETZSCHE, F. Escritos sobre educação. Tradução, apresentação e notas de Noéli Correia de Melo Sobrinho, 3. ed. São Paulo: Loyola/Rio de Janeiro: PUC-RJ, 2003.

PENA, Danilo Vitor. Resenha: WEBER, J. F. Formação (Bildung). Educação e Experimentação em Nietzsche. Estudos Nietzsche, Curitiba, v. 3, n. 1, p. 129-134, jan./jun. 2012.

RICCI, Ana Paula. Escolha e seletividade em Nietzsche: o tornar-se nos últimos escritos. Dissertação (Mestrado em Filosofia), 135p. São Paulo. Universidade São Judas Tadeu, 2007.

SOUSA, Mauro Araujo. O perspectivismo de Nietzsche e a compreensão. Líbero - São Paulo - v. 19, n. 37-A, p. 109-116, jul./dez. 2016.

STEGMAIER, Werner. As linhas fundamentais do pensamento de Nietzsche: coletânea de artigos 1985-2009. Organização de Jorge Luiz Viesenteiner e André Luis Muniz Garcia. Petrópolis, RJ: Vozes, 2013.

WEBER, José Fernandes. Formação (Bildung), educação e experimentação em Nietzsche. Londrina: Eduel, 2011. 
ZATTI, Vicente. Nietzsche e a Educação, 2005. Educa: educação online, disponível em: http://www.educacaoonline.com.br. Acesso em: 23/06/2018.

\section{DADOS DOS AUTORES:}

\section{LúCIA SCHNEIDER HARdT}

Doutorado em Educação pela Universidade Federal do Rio Grande do Sul/RS-Brasil. Professora da Universidade Federal de Santa Catarina/SC-Brasil.

\section{Paulo Becher Junior}

Doutorando do Programa de Pós-Graduação em Educação da Universidade Federal de Santa Catarina/SC-Brasil. Professor na Faculdade Cenecista de Joinville/SC-Brasil.

Submetido em: 2-6-2020

Aceito em: $17-11-2020$ 